\title{
Aspectos Reprodutivos e Perfil Hormonal dos Esteróides Sexuais do Pirarucu, Arapaima gigas (SCHINZ,1822), em Condições de Cativeiro
}

\author{
Leonardo Bruno Barbosa MONTEIRO ${ }^{1}$;Maria do Carmo Figueredo SOARES²; \\ Maria Teresa Jansem CATANHO ${ }^{3}$; Alexandre HONCZARYK ${ }^{4}$
}

\begin{abstract}
RESUMO
Esta pesquisa teve como objetivo caracterizar a reproduçáo e o perfil hormonal dos esteróides sexuais do pirarucu, Arapaima gigas, além de validar um aspecto do dimorfismo sexual secundário. O experimento foi realizado na Fazenda Santo Antônio II, em Presidente Figueredo-AM, no período de fevereiro de 2004 a fevereiro de 2005. Foram selecionados 24 exemplares e divididos em três grupos de oito peixes (grupo "A", "B" e "C" com pirarucus de mais de quatro anos de idade, com três anos e dois anos, respectivamente). Os pirarucus foram estocados em três tanques de $400 \mathrm{~m}^{2}$, um para cada grupo. Aspectos comportamentais, como o interesse por alimento, brigas, formaçáo de casais e presença de ninhos, foram observados ao longo de todo o experimento. Amostras de sangue foram coletadas mensalmente, de todos os peixes, observou-se a presença de uma mancha alaranjada no macho como uma característica sexual secundária. Foram mensurados os níveis de testosterona $(\mathrm{T})$, 17beta-estradiol $\left(\mathrm{E}_{2}\right)$ e 17alfa-hidroxi-progesterona $(17 \alpha \mathrm{OHP})$ através de radioimunoensaio (RIA) de fase sólida. Todos os machos dos grupos "A" e "B" puderam ser identificados pela mancha alaranjada na regiáo inferior da cabeça, corroborada pela concentração de testosterona, comprovando o conhecimento empírico dos ribeirinhos. Os níveis de $\mathrm{T}$ e $\mathrm{E}_{2}$ nos peixes do grupo "A" e "B" tiveram maiores picos no início do período de chuva, enquanto que o $17 \alpha \mathrm{OHP}$ teve oscilaçôes constantes e pequenos picos no final do período chuvoso, os peixes do grupo " $\mathrm{C}$ " acompanharam essa tendência em concentraçóes menores.
\end{abstract}

PALAVRAS-CHAVE: pirarucu, reprodução, esteróides sexuais, Arapaima gigas.

\section{Reproductive Aspects and Sexual Steroids Hormonal Profiles of Pirarucu, Arapaima gigas (SCHINZ,1822), in Captivity Conditions}

\begin{abstract}
The purpose of this study was to characterize the growth, reproduction and hormonal profile of pirarucu, Arapaima gigas, and validate one sexual dimorphism characteristic. The experiment was carried in the fish farm Santo Antonio II, Presidente Figueredo city in the state of Amazonas - Brazil, from February 2004 to February 2005. In the experiment, 24 fishes were selected and divided in three groups, with eight fish in each one. The pirarucus from "A" group were older than four years. In "B" group the fishes were three years old and in "C" group these were two years old. The pirarucus were stocked in $400 \mathrm{~m}^{2}$ excavated ponds, one pond for each group. Reproductive behavior like feeding interest, fights, pair formation and presence of nest were observed. Blood samples were taken monthly from all fishes during the experiment period, the sexual dimorphism characteristic was observed. Testosterone $(\mathrm{T}), 17 \mathrm{~b}$-estradiol $\left(\mathrm{E}_{2}\right)$ and 17ahidroxi-progesterona (17 $\mathrm{OHH}$ ) levels were measured by radioimunoassay (RIA) in solid phase. All males of group "A" and "B" could be identified by an orange mark under the head, and the levels of T validated this data, proving the empirical knowledge of river men. T and E levels of group "A" and "B" picked in the beginning of raining period and the $17 \alpha \mathrm{OHP}$ levels were higher in the end of raining period. The levels of these hormones in "C" group fishes followed the tendency of "A" and "B" group hormonal levels, but in lower concentration.
\end{abstract}

KEYWORDS: pirarucu, reproduction, sexual steroids, Arapaima gigas.

\footnotetext{
1 Pesquisador do Centro de Educação Tecnológica do Amazonas -contatos(92) 2126-7474. monteirolb@yahoo.com.br.

2 Departamento de Pesca e Aqüicultura - DEPAq. Universidade Federal Rural de Pernambuco - UFRPE. mcfs@depaq.ufrpe.br. Rua Dom Manoel de Medeiros, s/n, Dois Irmãos, Recife-PE - CEP 52171-900 Tel (81) 33206527

3 Departamento de Biofísica. Universidade Federal de Pernambuco - UFPE. mariajansem@terra.com.br Av. Prof. Moraes Rego, 1235 - Cidade Universitária, Recife - PE - CEP 50670-901.Tel: (81) 21268535.

${ }^{4}$ Coordenação de Pesquisas em Aqüicultura - CPAq. Instituto Nacional de Pesquisas da Amazônia - INPA. alex@inpa.gov.br. Avenida André Araújo, 2936, Petrópolis, Manaus - AM - CEP 69083-000. Tel (92) 36431919.
} 


\section{INTRODUÇÃO}

O pirarucu é uma espécie com grande potencialidade para a piscicultura devido à grande rusticidade, alto valor de mercado, excelente sabor da carne, porte e extraordinário desenvolvimento ponderal, que pode chegar até $10 \mathrm{~kg}$ no primeiro ano de vida (Imbiriba et al., 1985; Bard e Imbiriba, 1986; Imbiriba, 1991; Carvalho e Nascimento, 1992; Imbiriba, 2001).

Pode ser criado também de forma semi-intensiva e intensiva, destacando-se na criaçáo intensiva em virtude da respiração aérea. Esse mecanismo respiratório faz com que esta espécie possa tolerar altas densidades em ambientes com baixas concentraçóes de oxigênio dissolvido na água (Brauner e Val, 1996; Cavero et al., 2004). Além desta característica, os juvenis de pirarucu ainda podem tolerar altas concentraçóes de amônia (Cavero et al., 2004).

No entanto a principal dificuldade da criaçáo desta espécie é a produção de alevinos, visto que não existe o controle da reprodução além da alta mortalidade das larvas. A reduzida produção os torna altamente valorizados, inviabilizando a criação com fins econômicos. Neste elo da cadeia produtiva, algumas tecnologias estão sendo desenvolvidas, principalmente no que concerne à sobrevivência e tolerância às condiçôes adversas (Cavero et al., 2004), treinamento alimentar (Crescêncio, 2001) e exigências protéicas dos peixes nessa fase de vida (Ituassú, 2002).

O pirarucu desova de forma parcelada e tem hábitos de reprodução peculiares, formando casais, selecionando e isolando a área de desova, construindo ninho e liberando óvulos e esperma (Fontenele, 1948; Luling, 1964; Bard e Imbiriba, 1986; Venturieri e Bernadino, 1999; Imbiriba 2001).

Segundo Fontenele (1948) uma fêmea de 1,90 m de comprimento tem aproximadamente 180.505 oócitos em diferentes estágios de desenvolvimento. Apresenta comportamento de proteção a prole onde o macho guarda o ninho e após a eclosão dos ovos, mantém-se nas proximidades das larvas, defendendo-as dos predadores (Fontenele, 1948; Imbiriba, 1991; Venturiere e Bernardino, 1999).

O pirarucu é uma espécie lêntica e, segundo Hoar (1969), estas espécies não realizam migraçóes reprodutivas e fazem seus ninhos em locais com pouca movimentação de água. Este mesmo autor, também relatou que os ovos são, geralmente, maiores e em menor número do que nas espécies reofílicas.

A primeira reprodução em cativeiro do pirarucu foi obtida no Museu Paraense Emílio Goeldi, em 1939 (Venturiere e Bernardino, 1999). Foram poucas as observaçóes realizadas para se conhecer a reprodução da espécie, e todas foram em cativeiro (Fontenele, 1948 e 1953). Portanto, a reprodução juntamente com a larvicultura são atualmente fatores limitantes à criação deste peixe, sobretudo, porque ainda faltam muitos conhecimentos sobre o comportamento endócrino-reprodutivo do pirarucu.

Sabe-se que o processo reprodutivo em peixes é influenciado pelos fatores ambientais, que estimulam o sistema neuro-endocrinológico. Na maioria das espécies, os ciclos reprodutivos são anuais. Este processo nos teleósteos ocorre com a maturação das gônadas, seguidas da ovulação (fêmeas) ou espermiação (machos) e liberação dos óvulos ou esperma (Harvey e Carolsfeld, 1993).

Os princípios do controle endócrino da reprodução em vários peixes são similares, mas os detalhes variam consideravelmente entre as espécies. A elucidação dos mecanismos em uma espécie de peixe meramente contribui, mas não resolve os problemas de outra espécie (Yaron e Zohar, 1993).

Muitos peixes de interesse comercial apresentam disfunçôes reprodutivas quando criados em cativeiro (Zohar e Mylonas, 2001). No entanto, a reprodução, segundo Donaldson (1996), tem sido considerada a chave que abre a porta para o sucesso das primeiras fases larvais, metamorfoses e engorda até o tamanho comercial. Sobretudo, porque a reprodução em cativeiro permite a domesticação e o uso de técnicas de melhoramento genético (Zohar e Mylonas, 2001).

Uma das disfunçóes reprodutivas apresentadas pelo pirarucu parece ser a pouca produção de sêmen. Venturieri e Bernardino (1999) relataram esta característica como um dos maiores entraves na reprodução desta espécie em cativeiro.

O acompanhamento das variaçóes hormonais, subsidiado com um modelo já descrito, permite intervir racionalmente no processo reprodutivo. Segundo Aida (1988), estas são as razóes para se estudar as secreçóes hormonais durante o processo natural de desova. As informaçóes obtidas nesses estudos têm um lugar importante na pesquisa aplicada, particularmente na indução à desova.

O presente trabalho teve como objetivo traçar o perfil da variação hormonal dos esteróides sexuais durante um ciclo anual, em condiçóes de cativeiro no estado do Amazonas.

\section{MATERIAL E MÉTODOS}

O experimento foi realizado na fazenda Santo Antônio II, localizada no município de Presidente Figueredo - AM, no quilômetro 47 da estrada AM 240, no período de fevereiro de 2004 a fevereiro de 2005.

Foram utilizados vinte e quatro pirarucus, Arapaima gigas, separados em três grupos de acordo com a idade, sendo oito peixes em cada grupo. O grupo "A", composto de peixes com idade superior a quatro anos, o grupo "B" com peixes de três anos e o grupo "C" com peixes de dois anos. Cada grupo foi 
colocado em viveiros escavados em terreno natural, com área de $400 \mathrm{~m}^{2}$, numa densidade de 1 peixe $/ 50 \mathrm{~m}^{2}$.

Nos pirarucus dos grupos " $\mathrm{A}$ " e "B" foi verificada a existência de uma mancha de coloração alaranjada na regiáo inferior da cabeça, entre o opérculo e a cavidade bucal e mais fortemente marcada na época da reprodução, utilizada neste experimento para a identificaçáo do macho.

Os peixes dos grupos "B" e "C" provieram de reprodução em cativeiro, passaram por treinamento alimentar e, portanto, foram alimentados com ração extrusada comercial, específica para carnívoros, com $40 \%$ de proteína bruta e $3.000 \mathrm{kcal} / \mathrm{kg}$ de energia bruta.

Os peixes do grupo "A" foram peixes capturados no ambiente natural, na fase juvenil e, conseqüentemente, não receberam o treinamento alimentar. Permaneceram aclimatados por mais de dois anos em viveiros de $1000 \mathrm{~m}^{2}$, onde foram alimentados, neste período, com peixes regionais (jaraqui, Semaprochilodus sp.; curimatá, Prochilodus sp.; tambaqui, Colossoma macropomum; sardinha, Triportheus sp.).

Nas condiçôes experimentais, todos os peixes foram alimentados duas vezes ao dia, até a saciedade aparente. Os peixes do grupo "B" e "C" foram alimentados com ração, com $40 \%$ de proteína bruta e $3.000 \mathrm{kcal} / \mathrm{kg}$ de energia bruta, e os do grupo "A", com peixes nativos mortos (jaraqui, Semaprochilodus sp.; curimatã, Prochilodus sp.; tambaqui, Colossoma macropomum; sardinha, Triportheus sp.).

Os três viveiros foram povoados por tilápias, Oreochromis sp., as quais serviram de alimento forrageiro para todos os pirarucus dos grupos "A", "B" e "C" da pesquisa.

Para a identificação dos pirarucus, cada um foi marcado com etiquetas de nylon numeradas do tipo âncora, que foram colocadas dois centímetros abaixo da nadadeira dorsal, no lado esquerdo (Figura 1).

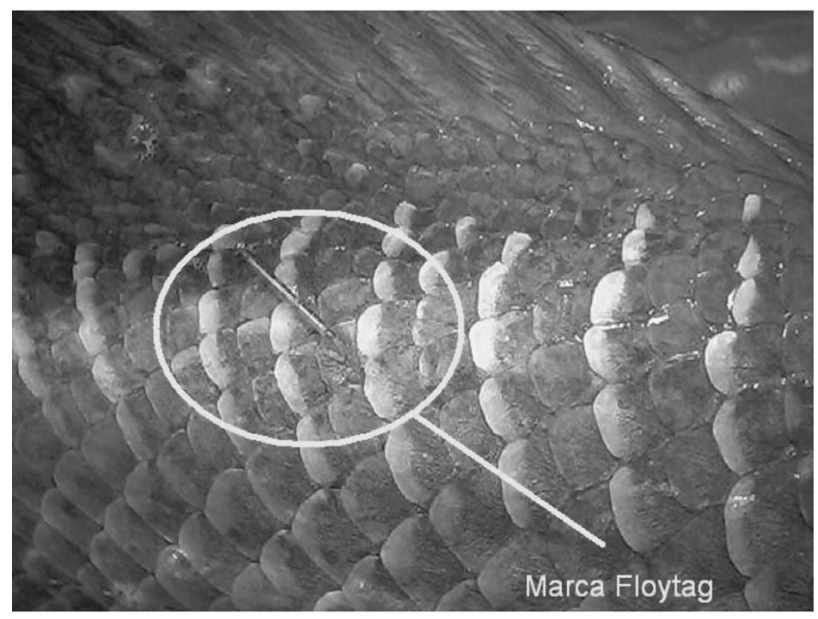

Figura 1 - Marcação com etiqueta de nylon em exemplar de pirarucu, Arapaima gigas.
A técnica de coleta utilizada foi o arrasto, sendo os pirarucus agrupados em um dos cantos do viveiro, para que fossem capturados manualmente e colocados em maca para transporte (Figura 2). Após a captura mensal, os peixes foram levados para um tanque de fibra de vidro de $3 \mathrm{~m}^{2}$ e estocados para a mensuração biológica.

Procedeu-se a leitura da marca e mensurou-se o comprimento total e peso com trena de $3 \mathrm{~m}$ e balança Fillizola de $50 \mathrm{~kg}$, respectivamente, para acompanhar o crescimento dos pirarucus em cativeiro. A existência de ninhos foi verificada, e o seu tamanho foi considerando a área escavada e depressão formada no fundo do viveiro (ninho do tipo "buraco").

Para a coleta de sangue, os animais foram colocados em cima de uma mesa e imobilizados dentro da maca de transporte. As amostras de sangue foram coletadas com seringas heparinizadas, por punção da veia caudal (Figura 3) e após centrifugação, separou-se o plasma para posterior análise dos hormônios esteróides (testosterona total, 17beta-estradiol e 17alfa-hidroxi-progesterona).

As amostras de plasma foram congeladas em gelo seco $\left(-70^{\circ} \mathrm{C}\right)$, para o transporte da fazenda até o laboratório em Manaus na Coordenação de Pesquisas em Aqüicultura (CPAq) do Instituto Nacional de Pesquisas da Amazônia (INPA), e mantidas em botijão criogênico a uma temperatura de $-190^{\circ} \mathrm{C}$. Posteriormente, foram transportadas de Manaus$\mathrm{AM}$ até Recife-PE, conservadas em gelo seco e mantidas em Biofrezzer à $-80^{\circ} \mathrm{C}$ até as análises hormonais.

Foram medidos os níveis de testosterona total, 17betaestradiol $\left(17 \mathrm{bE}_{2}\right)$ e 17alfa-hidroxi-progesterona (17aHP) no plasma, através de radioimunoensaio (RIE) de fase sólida, com hormônios marcados com _ ${ }^{125}$ I, utilizando-se kits comerciais Coat-A-Count, da Diagnostic Products Corporation (DPC).

Foram mensurados oxigênio dissolvido, $\mathrm{pH}$, dureza total, alcalinidade, nitrito, amônia e temperatura da água dos

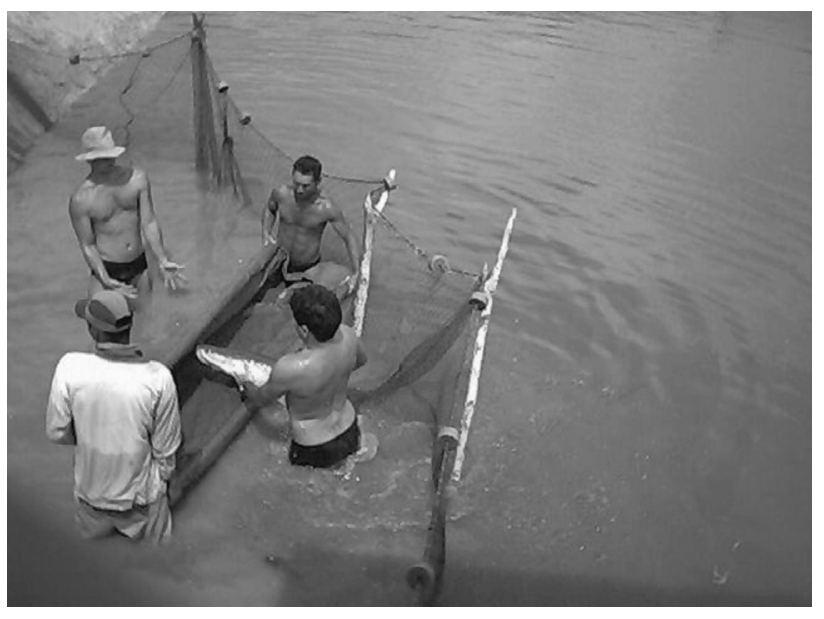

Figura 2 - Coleta manual do pirarucu, Arapaima gigas e transporte em maca. 
viveiros, através do polikit da Alfakit Produtos Ltda. Para a melhor caracterização ambiental, foram observados os dados de precipitação, temperatura do ar e disponibilidade atual de água no solo (DAAS), obtidos do Instituto Nacional de Meteorologia (INMET), na subestação de Manaus, através do site http://www.agritempo.gov.br/agroclima/.

Foram calculados as médias, desvio padrão, variância, coeficiente de variação e valores máximos e mínimos para as variáveis concentração de testosterona total, de 17 betaestradiol e de 17alfa-hidroxi-progesterona, dos três grupos de peixes. O grupo "A" e "B" ainda tiveram os valores destas variáveis separados por sexo em função do dimorfismo sexual apresentado.

A diferenciação de machos e fêmeas pelos níveis hormonais, comparação dos dados biométricos e dos índices zootécnicos foram realizados através de análise de variância (ANOVA), seguida do teste de Student-Newman-Keuls. A correlação de Pearson foi utilizada para agrupar os peixes com variaçóes hormonais relacionadas durante o experimento, além de verificar a correlação da variação entre os hormônios.

\section{RESULTADOS}

Os dados das variáveis físicas e químicas da água estão apresentados na Tabela 1. As medidas foram feitas de 11:30 às 14:00 horas e a menor concentração de oxigênio dissolvido foi de $4 \mathrm{mg} / \mathrm{L}$, nos viveiros dos grupos "A" e "B", e $5 \mathrm{mg} / \mathrm{L}$, no viveiro do grupo "C".

No viveiro do grupo "A", o $\mathrm{pH}$ variou entre 6 e 7 e a temperatura entre $29^{\circ} \mathrm{C}$ e $32^{\circ}$. C. A maior concentração de amônia neste viveiro foi de $4 \mathrm{mg} / \mathrm{L}$. No viveiro do grupo "B", o pH e a temperatura variaram de 5 a 7 e $29^{\circ} \mathrm{C}$ a $33^{\circ} \mathrm{C}$, respectivamente, e a amônia teve $1,5 \mathrm{mg} / \mathrm{L}$ como a maior concentração, durante todo o experimento. No grupo " $\mathrm{C}$ ", a maior concentração de amônia foi de $2 \mathrm{mg} / \mathrm{L}$. Este viveiro teve valores de $\mathrm{pH}$ variando entre 5 e 8 , e temperatura entre $29^{\circ} \mathrm{C}$ a $32^{\circ} \mathrm{C}$ (Tabela 1 ).

Considerando que os fatores ambientais são os reguladores da periodicidade dos ciclos reprodutivos em teleósteos (Billard et al., 1978; Lam, 1983), a Figura 3 (A, B e C) exibe os dados de temperatura do ar, precipitação e disponibilidade atual de água no solo (DAAS), em Manaus-AM, durante o período de fevereiro de 2004 a fevereiro de 2005 . O período de maior precipitação foi de fevereiro a junho e de novembro a janeiro (Figura 3B). A disponibilidade atual de água no solo (DAAS) é um dado que delimita bem o período das chuvas, e este foi de março a meados de julho (Figura 3C).

Em abril, junho e julho foi observada a falta de interesse dos peixes do grupo "A" por alimento. O mesmo aconteceu no grupo "B", nos meses de abril, junho, julho, setembro

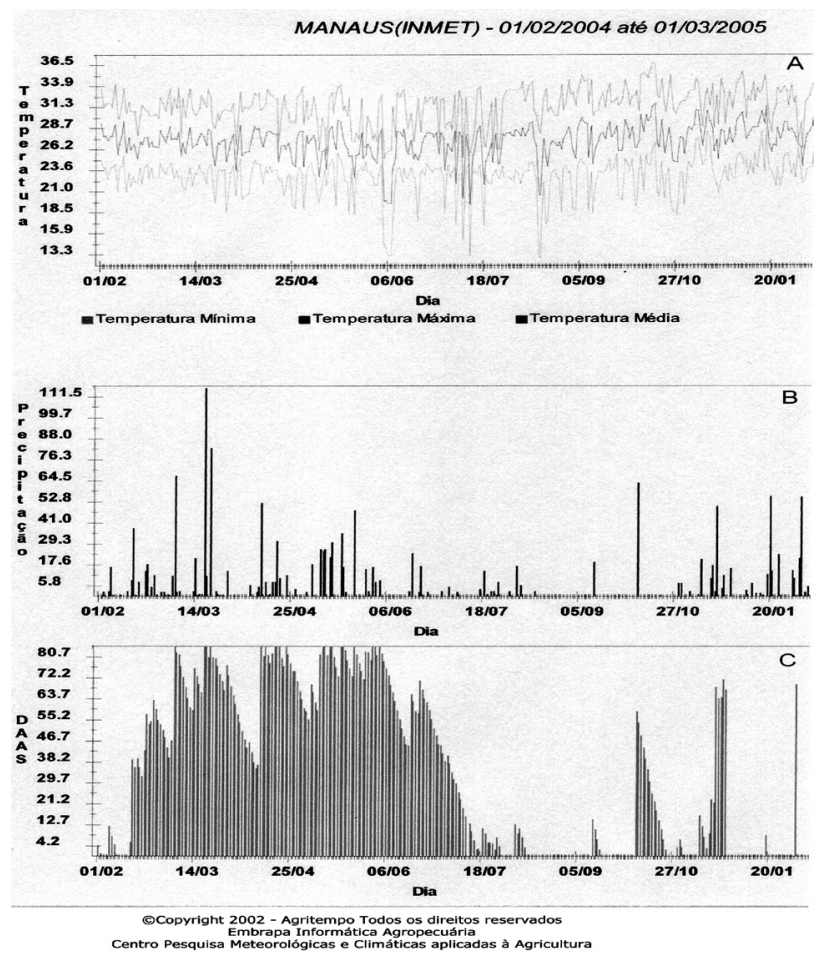

Figura 3 - Dados de temperatura do ar (A), precipitação (B) e disponibilidade atual de água no solo (DAAS), em Manaus-AM, durante o período de fevereiro de 2004 a fevereiro de 2005.

e outubro. Durante esses períodos, foi registrada uma movimentaçáo intensa na água, nas proximidades dos ninhos e registradas como brigas. No entanto não foi observada a formação de casais (Tabela 2).

A deposição dos gametas em ninhos é uma estratégia de reprodução do pirarucu, onde os ovos são protegidos pelos machos. A presença destes foi verificada nos meses de abril, maio, junho, julho e agosto, para o viveiro do grupo "A", e nos meses de junho, julho, agosto, setembro, outubro e novembro, no viveiro do grupo "B" (Tabela 2), e tinham em torno de 50 $\mathrm{cm}$ de diâmetro e cerca de $15 \mathrm{~cm}$ de profundidade.

Nos peixes do grupo "C", não foi observado, nenhum desses comportamentos, pois se tratavam de pirarucus que ainda não entraram na fase reprodutiva.

Os machos apresentaram uma mancha alaranjada na parte inferior da cabeça, diferindo das fêmeas. As manchas permaneceram durante todo o período de coleta, variando apenas em intensidade, sendo mais intensa nos meses onde foram anotados os comportamentos reprodutivos apresentados na Tabela 2.

Nas fêmeas, esta mancha alaranjada, na regiâo inferior da cabeça, foi ausente, permanecendo alva, apesar da intensificaçáo na coloração em alguns meses (Figuras 4 e 5). 
Tabela 1 - Dados das variáveis físicas e químicas da água de viveiros de pirarucu, Arapaima gigas, durante o período de março de 2004 a fevereiro de 2005.

\begin{tabular}{|c|c|c|c|c|c|c|c|c|c|c|c|c|}
\hline \multicolumn{13}{|c|}{ Viveiro "A" } \\
\hline Variáveis & mar & $a b r$ & mai & jun & jul & ago & set & out & nov & dez & Jan & fev \\
\hline Oxigênio Dissolvido (mg/l) & 7 & 8 & 5 & 6 & 9 & 8 & 7 & 8 & 4 & 5 & 7 & 6 \\
\hline pH & 6 & 6,5 & 6 & 7 & 6,5 & 7 & 6,5 & 7 & 7 & 6,5 & 6 & 6,5 \\
\hline Dureza (mg/l) & 30 & 20 & 20 & 30 & 10 & 20 & 10 & 50 & 30 & 20 & 30 & 20 \\
\hline Alcalinidade (mg/l) & 10 & 20 & 20 & 20 & 10 & 10 & 20 & 30 & 10 & 20 & 10 & 20 \\
\hline Nitrito (ppm) & 0 & 0 & 0 & 0 & 0 & 0 & 0 & 0 & 0 & 0 & 0 & 0 \\
\hline Amônia (mg/l) & 1 & 2 & $<0,5$ & 1 & $<0,5$ & 1 & 2 & 4 & 1 & $<0,5$ & 1 & 1 \\
\hline Temperatura $\left({ }^{\circ} \mathrm{C}\right)$ & 29 & 30 & 30 & 31 & 29 & 32 & 30 & 30 & 32 & 31 & 32 & 29 \\
\hline \multicolumn{13}{|c|}{ Viveiro "B" } \\
\hline Variáveis & mar & $a b r$ & mai & jun & jul & ago & set & out & nov & dez & Jan & fev \\
\hline Oxigênio Dissolvido (mg/l) & 6 & 5 & 8 & 8 & 9 & 7 & 4 & 7 & 6 & 6 & 5 & 6 \\
\hline $\mathrm{pH}$ & 6,5 & 6 & 6 & 7 & 6 & 6 & 6,5 & 6 & 5 & 5,5 & 6 & 6 \\
\hline Dureza (mg/l) & 30 & 200 & 40 & 30 & 30 & 50 & 100 & 100 & 200 & 200 & 150 & 100 \\
\hline Alcalinidade (mg/l) & 10 & 10 & 20 & 20 & 10 & 10 & 20 & 20 & 20 & 30 & 20 & 20 \\
\hline Nitrito (ppm) & 0 & 0 & 0 & 0 & 0 & 0 & 0 & 0 & 0 & 0 & 0 & 0 \\
\hline Amônia (mg/l) & $<0,5$ & 0,5 & 1 & $<0,5$ & 0,5 & 1 & 1 & 1,5 & 0,5 & $<0,5$ & 1 & 1 \\
\hline Temperatura $\left({ }^{\circ} \mathrm{C}\right)$ & 30 & 31 & 30 & 32 & 29,5 & 29 & 30 & 30 & 33 & 32 & 30 & 29 \\
\hline \multicolumn{13}{|c|}{ Viveiro "C" } \\
\hline Variáveis & mar & $a b r$ & mai & jun & jul & ago & set & out & nov & dez & Jan & fev \\
\hline Oxigênio Dissolvido (mg/l) & 6 & 6 & 7 & 5 & 5 & 6 & 7 & 8 & 5 & 6 & 5 & 6 \\
\hline $\mathrm{pH}$ & 6,5 & 6,5 & 7 & 6,5 & 6,5 & 7 & 6 & 6,5 & 6,5 & 6 & 6 & 6 \\
\hline Dureza (mg/l) & 50 & 40 & 50 & 30 & 50 & 60 & 40 & 80 & 70 & 60 & 60 & 40 \\
\hline Alcalinidade (mg/l) & 20 & 10 & 30 & 30 & 20 & 20 & 10 & 30 & 10 & 20 & 30 & 20 \\
\hline Nitrito (ppm) & 0 & 0 & 0 & 0 & 0 & 0 & 0 & 0 & 0 & 0 & 0 & 0 \\
\hline Amônia (mg/l) & 2 & 1 & 1 & $<0,5$ & $<0,5$ & 1 & 1 & 2 & 2 & 1 & 2 & 1 \\
\hline Temperatura $\left({ }^{\circ} \mathrm{C}\right)$ & 30 & 30 & 31 & 30 & 29,5 & 30 & 31 & 31 & 32 & 31 & 31 & 29 \\
\hline
\end{tabular}

Tabela 2 - Aspectos do comportamento reprodutivo do pirarucu, Arapaima gigas, durante o período de fevereiro de 2004 a fevereiro de 2005.

\begin{tabular}{|c|c|c|c|c|c|c|c|c|c|c|c|c|c|c|}
\hline \multirow{2}{*}{$\begin{array}{l}\text { Comportamento } \\
\text { reprodutivo }\end{array}$} & \multirow{2}{*}{ Grupo } & \multicolumn{11}{|c|}{2004} & \multicolumn{2}{|c|}{2005} \\
\hline & & Fev & Mar & Abr & Mai & Jun & Jul & Ago & Set & Out & Nov & Dez & Jan & Fev \\
\hline \multirow{2}{*}{ Formação de casal } & "A" & $n$ & $n$ & $\mathrm{n}$ & $\mathrm{n}$ & $n$ & $\mathrm{n}$ & $\mathrm{n}$ & $n$ & $n$ & $\mathrm{n}$ & $n$ & $\mathrm{n}$ & $n$ \\
\hline & "B" & $\mathrm{n}$ & $\mathrm{n}$ & $\mathrm{n}$ & $\mathrm{n}$ & $\mathrm{n}$ & $\mathrm{n}$ & $\mathrm{n}$ & $\mathrm{n}$ & $\mathrm{n}$ & $\mathrm{n}$ & $\mathrm{n}$ & $\mathrm{n}$ & $\mathrm{n}$ \\
\hline \multirow{2}{*}{ Interesse por alimento } & "A" & s & s & n & s & n & n & s & s & s & s & s & s & s \\
\hline & "B" & $s$ & $s$ & $\mathrm{n}$ & s & n & n & s & n & n & $\mathrm{s}$ & $\mathrm{s}$ & s & s \\
\hline \multirow{2}{*}{ Presença de ninho } & "A" & $\mathrm{n}$ & $\mathrm{n}$ & s & s & $\mathbf{s}$ & $\mathbf{s}$ & s & $\mathrm{n}$ & $\mathrm{n}$ & $\mathrm{n}$ & $\mathrm{n}$ & $\mathrm{n}$ & $n$ \\
\hline & "B" & $n$ & $\mathrm{n}$ & $\mathrm{n}$ & $\mathrm{n}$ & $s$ & $s$ & s & $s$ & $s$ & $s$ & $n$ & $n$ & $n$ \\
\hline \multirow{2}{*}{ Brigas } & "A" & $n$ & $n$ & $s$ & $\mathrm{n}$ & $s$ & $\mathbf{s}$ & $\mathrm{n}$ & $n$ & $n$ & $\mathrm{n}$ & $n$ & $n$ & $n$ \\
\hline & "B" & $\mathrm{n}$ & $\mathrm{n}$ & $\mathrm{n}$ & $\mathrm{n}$ & $s$ & $s$ & $\mathrm{n}$ & $s$ & $s$ & $\mathrm{n}$ & $\mathrm{n}$ & $\mathrm{n}$ & $\mathrm{n}$ \\
\hline
\end{tabular}

S --> sim, n -->não 
As Figuras 6, 7 e 8 mostram o perfil dos hormônios esteróides sexuais do pirarucu, Arapaima gigas, do grupo "A", ao longo do período experimental sob as condiçôes de cativeiro.

Os machos do grupo "A" tiveram aumento nas concentraçôes de testosterona total nos meses de março, dezembro e janeiro, e uma pequena elevação nos níveis nos meses de junho a agosto. Neste grupo se destaca o macho 2 que tem suas concentraçóes bastante elevadas nos meses de março e janeiro (Figura 6).

As fêmeas tiveram aumento crescente nas concentraçóes de testosterona total entre os meses de outubro a janeiro. No período de fevereiro a maio observa-se um nível basal de testosterona nesses peixes. Entre as fêmeas destacam-se os peixes 7 e 8 que têm as concentraçóes de testosterona elevadas nos meses de outubro a janeiro (Figura 6).

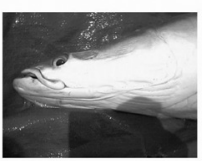

Peixe 1 (fềmea)

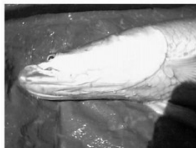

Peixe 5 (fềmea)

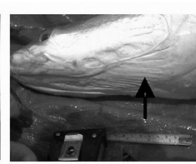

Peixe 2 (macho)

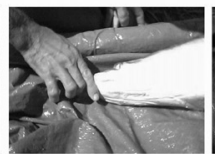

Peixe 6 (fềmea)

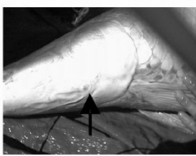

Peixe 3 (macho)

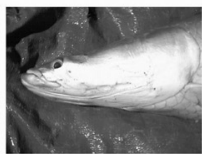

Peixe 7

(fêmea)

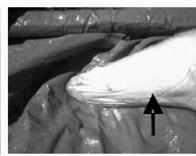

Peixe 4

(macho)

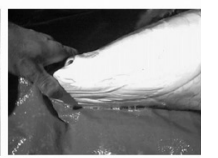

Peixe 8

(fêmea)
Figura 4 - Diferenciação sexual dos pirarucus, Arapaima gigas, do grupo "A" através da mancha vermelha (característica sexual secundária).
As concentrações de 17 beta-estradiol nos machos do grupo "A" foram praticamente constantes e, nas fêmeas, os aumentos de concentração ocorreram nos meses de março, maio, agosto, novembro e janeiro. As fêmeas 5 e 6 tiveram valores bem elevados e acima da média obtida (Figura 7).

A $17 \alpha \mathrm{OHP}$ teve sua concentração aumentada nos meses de fevereiro, junho, novembro e dezembro, tanto para machos quanto para fêmeas. Entre as fêmeas, o peixe 7 teve um pico de concentraçáo em março, o peixe 8 em junho e o peixe 5 em novembro. Nos machos, o peixe 4 teve um pico em maio, o peixe 3 em junho e o peixe 2 em dezembro (Figura 8).

As Figuras 9, 10 e 11 mostram o perfil dos hormônios esteróides sexuais do pirarucu, Arapaima gigas, do grupo "B", ao longo do período experimental sob as condições de cativeiro.

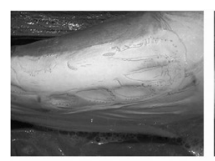

Peixe 1 (fêmea)

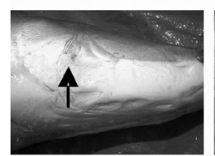

Peixe 5 (macho)

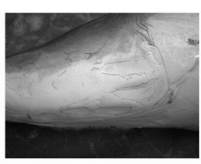

Peixe 2 (fêmea)

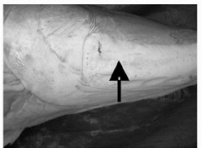

Peixe 6 (macho)

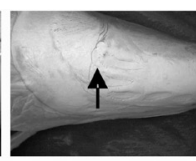

Peixe 3 (macho)

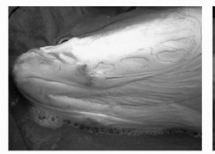

Peixe 7

(fêmea)

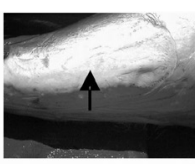

Peixe 4 (macho)

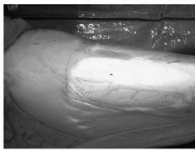

Peixe 8

(fêmea)

Figura 5 - Diferenciação sexual dos pirarucus, Arapaima gigas, do grupo "B" através da mancha vermelha (característica sexual secundária).

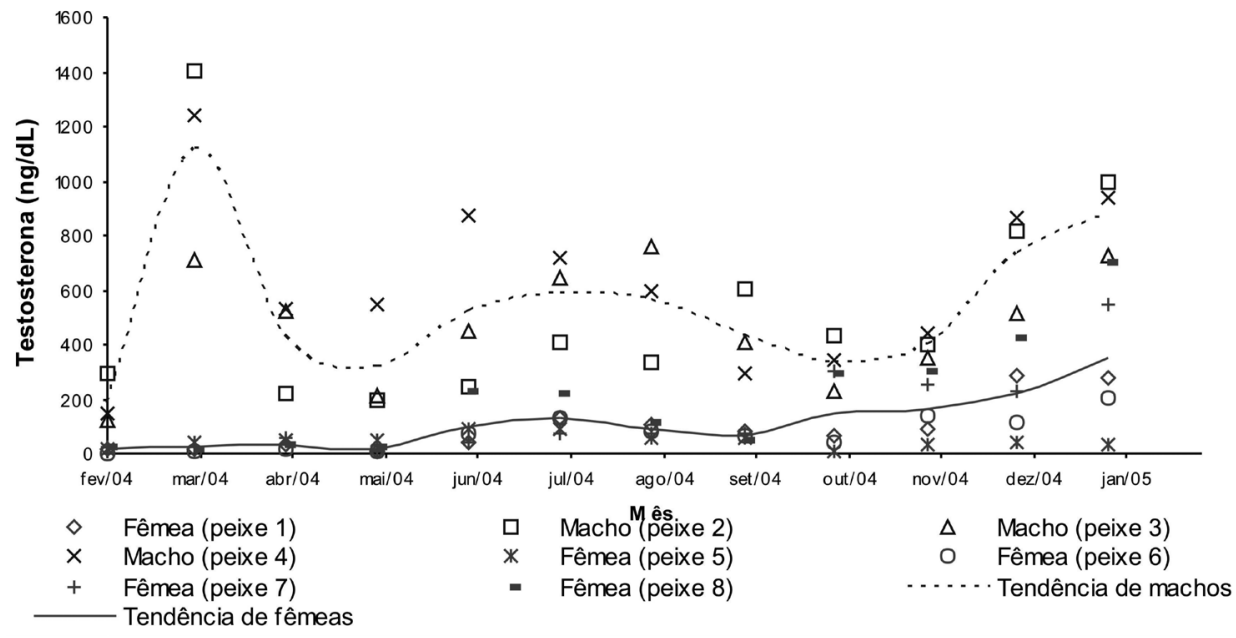

Figura 6 - Concentração de testosterona total em machos e fêmeas de pirarucu, Arapaima gigas, do grupo A. 


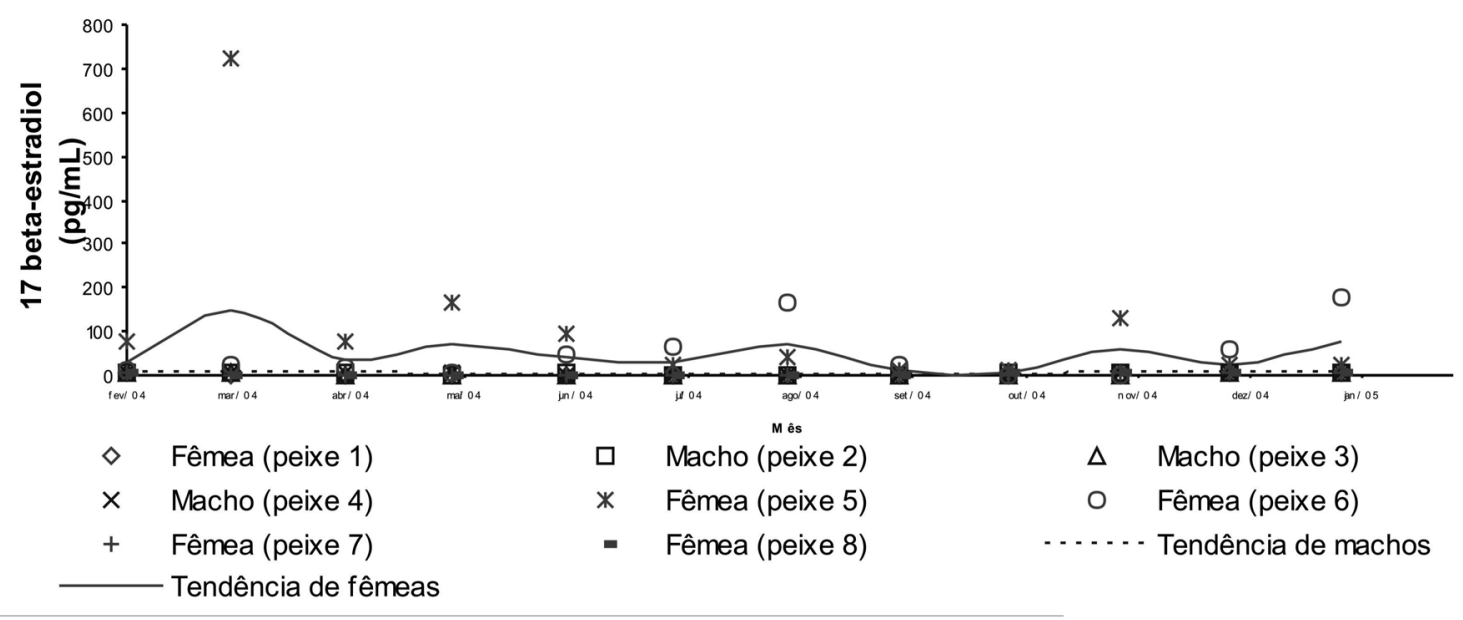

Figura 7- Concentração de 17beta-estradiol em machos e fêmeas de pirarucu, Arapaima gigas, do grupo A.

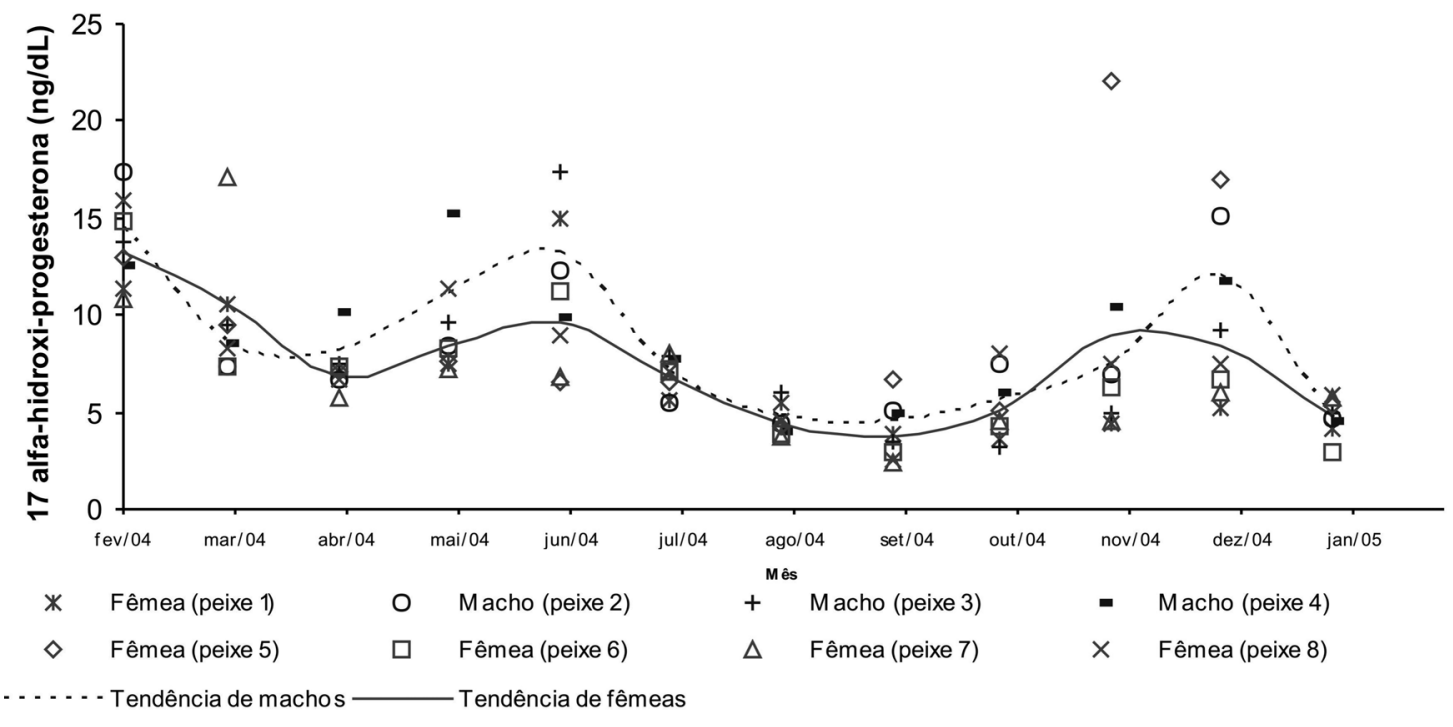

Figura 8 - Concentração de 17alfa-hidroxi-progesterona em machos e fêmeas de pirarucu, Arapaima gigas, do grupo A.

As concentraçôes de testosterona em machos do grupo "B" foram elevadas nos meses de fevereiro, março, maio, dezembro e janeiro. Nas fêmeas, as concentraçôes foram elevadas nos meses de março, maio, dezembro e janeiro (Figura 9), apresentando valores maiores do que os peixes do grupo "A".

As concentraçôes de 17beta-estradiol nos machos deste grupo apresentaram baixas variaçóes. Nas fêmeas, houve aumento de concentração nos meses de fevereiro, maio, dezembro e janeiro. Neste grupo de peixes, destaca-se o peixe
7, que teve picos de concentraçáo mais elevados que os dos outros peixes (Figura 10).

Na Figura 11, está descrita a variação de $17 \alpha \mathrm{OHP}$, a qual teve sua concentraçáo elevada nos machos, no mês de agosto, e nas fêmeas, nos meses de março, junho, agosto e outubro. Entre os machos, destacam-se o peixes 3 e 6 , com seus picos em agosto, e entre as fêmeas, os peixes 2 e 8 , por suas concentraçóes elevadas nos meses de março e outubro, respectivamente. 


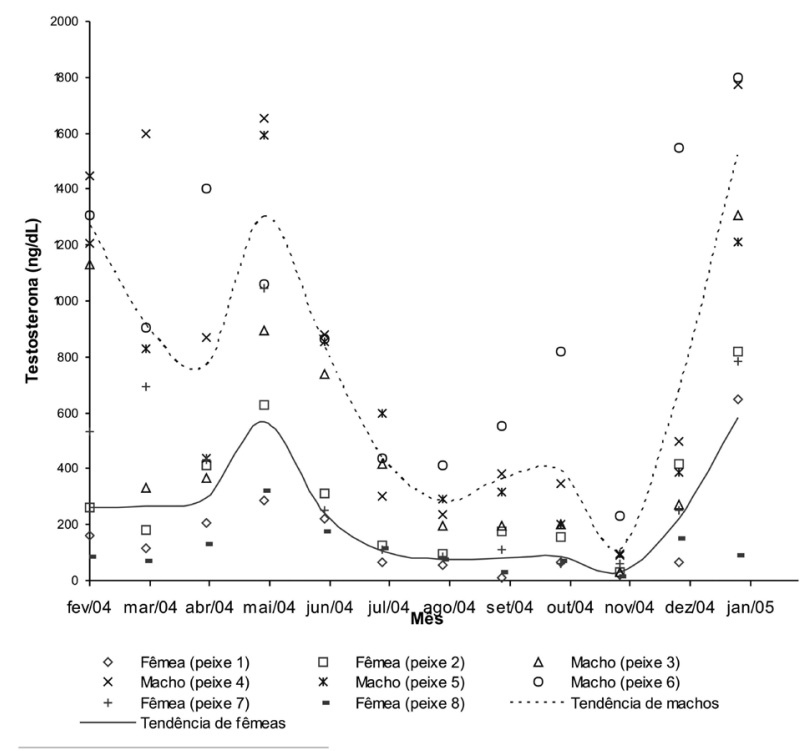

Figura 9 - Concentração de testosterona total em machos e fêmeas de pirarucu, Arapaima gigas, do grupo B.

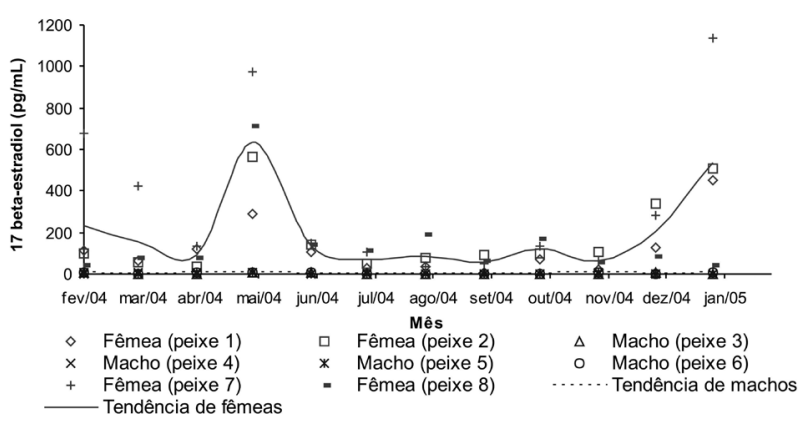

Figura 10 - Concentração de 17beta-estradiol em machos e fêmeas de pirarucu, Arapaima gigas, do grupo B.

As Figuras 12, 13 e 14 mostram o perfil dos hormônios esteróides sexuais do pirarucu, Arapaima gigas, do grupo "C", ao longo do período experimental sob as condiçōes de cativeiro.

Neste grupo, não foi possível fazer a separação por sexo em função da idade dos indivíduos, a qual não permitiu uma segura distinção de machos e fêmeas, a partir da mancha na regiáo inferior da cabeça.

As concentraçóes de testosterona total dos pirarucus do grupo "C" foram elevadas nos meses de abril, outubro, dezembro e janeiro. Dentre os pirarucus deste grupo, os peixes 1, 2, 4, 6 e 7 tiveram concentraçôes mais elevadas deste hormônio (Figura 12).

A concentração de 17beta-estradiol elevou-se nos meses de março, junho, outubro, novembro, dezembro e janeiro.

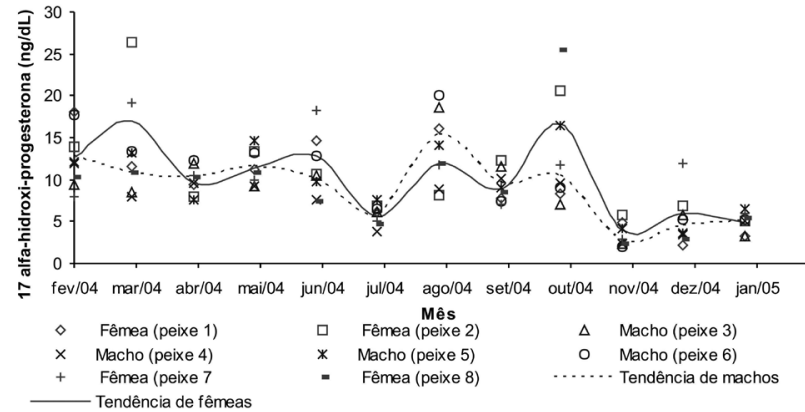

Figura 11- Concentração de 17alfa-hidroxi-progesterona em machos e fêmeas de pirarucu, Arapaima gigas, do grupo B.

Os peixes 1, 3, 4 e 5 apresentaram níveis mais altos no final do período experimental (Figura 13).

Neste grupo, a $17 \alpha \mathrm{OHP}$ teve a concentração elevada nos meses de maio, junho e janeiro. Os peixes 3, 5, 6 e 7 obtiveram picos de concentraçóes acima da média nos meses de maio (peixe 5 e 7) e junho (peixe 3, 5 e 6) (Figura 14).

A Tabela 3 sumariza os dados da caracterização hormonal do pirarucu, destacando os dados anuais de média, desvio padrão, variância, coeficiente de variação e valores máximos e mínimos da concentraçáo de testosterona total, 17betaestradiol e 17alfa-hidroxi-progesterona, nos pirarucus dos grupos "A", "B" e "C".

A análise de variância (ANOVA) e o teste de StudentNewman-Keuls demonstraram que as concentraçóes de testosterona total e 17 beta-estradiol foram diferentes entre machos e fêmeas do mesmo grupo $(\mathrm{p}<0,05)$. Entretanto as concentraçóes de $17 \alpha \mathrm{OHP}$ de machos e fêmeas do mesmo grupo não diferiram estatisticamente (Tabela 4).

Nas concentraçóes de testosterona total, 17beta-estradiol e $17 \alpha \mathrm{OHP}$ das fêmeas de grupos diferentes ocorreram diferenças

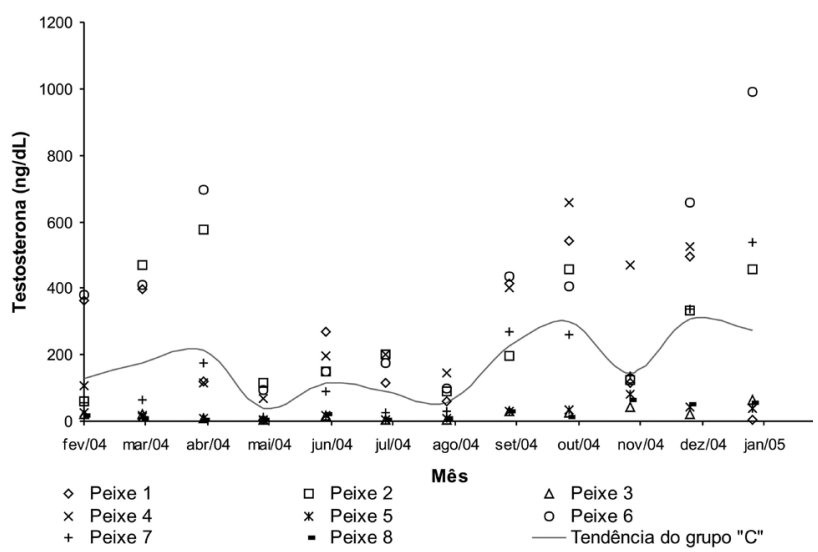

Figura 12 - Concentração de testosterona em pirarucu, Arapaima gigas, do grupo $\mathrm{C}$. 


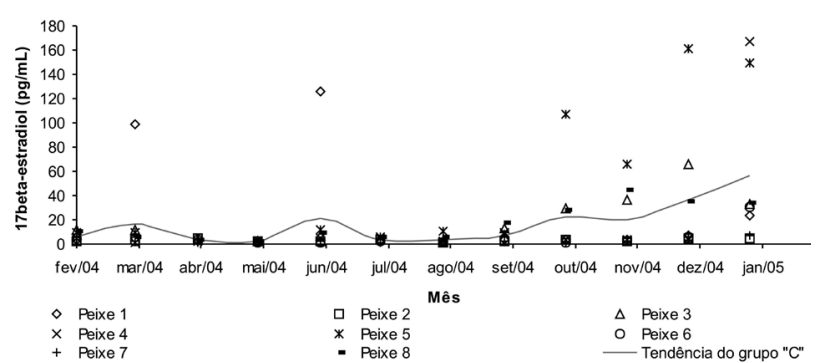

Figura 13 - Concentração de 17beta-estradiol em pirarucu, Arapaima gigas, grupo $\mathrm{C}$.

significativas $(\mathrm{p}<0,05)$. Os machos de grupos diferentes não diferiram significativamente nas concentraçôes de 17 betaestradiol e $17 \alpha \mathrm{OHP}$, mas diferiram nas concentraçôes de testosterona total (Tabela 5).

As Tabelas 6 e 7 apresentam a correlação entre testosterona, 17beta-estradiol e 17alfa-hidroxi-progesterona de machos e fêmeas, respectivamente, do grupo "A". Nos machos, a variação

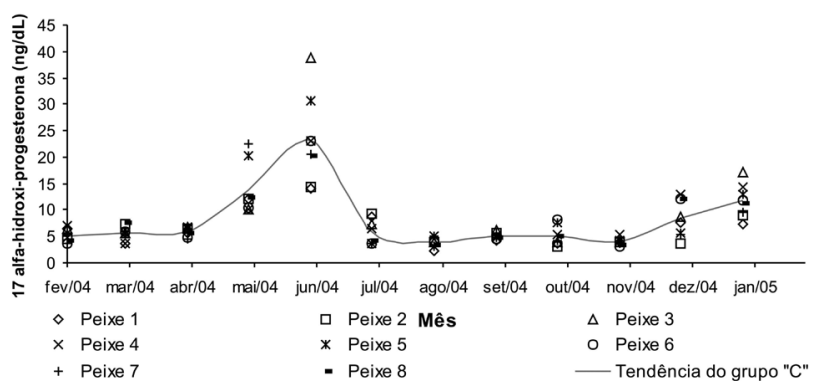

Figura 14 - Concentração de 17alfa-hidroxi-progesterona em pirarucu, Arapaima gigas, grupo C.

de testosterona está correlacionada com a variação de 17 betaestradiol, assim como a variação de 17 beta-estradiol está correlacionada com a variação de 17alfa-hidroxi-progesterona (Tabela 6). Nas fêmeas, verificou-se uma correlação negativa entre a variação de testosterona e 17 alfa-hidroxi-progesterona (Tabela 7).

Tabela 3 - Média aritmética, desvio padrão, variância, coeficiente de variação e valores máximos e mínimos de comprimento total, peso, ganho de peso, crescimento e fator de condição nos pirarucus, Arapaima gigas, dos grupos "A", "B" e "C", durante o período de fevereiro de 2004 a fevereiro de 2005.

\begin{tabular}{|c|c|c|c|c|c|c|}
\hline \multirow{2}{*}{ Variável } & \multirow{2}{*}{ Estatística Descritiva } & \multicolumn{2}{|c|}{ Grupo "A" } & \multicolumn{2}{|c|}{ Grupo "B" } & \multirow{2}{*}{ Grupo "C" } \\
\hline & & Machos & Fêmeas & Machos & Fêmeas & \\
\hline \multirow{6}{*}{ Testosterona total (ng/dL) } & Média & 542,43 & 112,18 & 739,94 & 235,22 & 172,39 \\
\hline & Desvio Padrão & 302,83 & 136,5 & 517,61 & 240,8 & 205,45 \\
\hline & Variância & 91708 & 18632,1 & 267918 & 57984,2 & 42208,3 \\
\hline & C. V. & $55,83 \%$ & $121,67 \%$ & $69,95 \%$ & $102,37 \%$ & $119,18 \%$ \\
\hline & Máximo & 1404,5 & 705,09 & 1800,52 & 1042,95 & 990,77 \\
\hline & Mínimo & 122,41 & 3,5 & 30,81 & 12,01 & 2,58 \\
\hline \multirow{6}{*}{ 17beta-estradiol (pg/mL) } & Média & 3,26 & 35,25 & 3,41 & 198,53 & 16,51 \\
\hline & Desvio Padrão & 1,36 & 99,94 & 1,207 & 248,09 & 33,78 \\
\hline & Variância & 1,86 & 9987,84 & 1,46 & 61550,3 & 1140,72 \\
\hline & C. V. & $41,78 \%$ & $283,52 \%$ & $35,35 \%$ & $124,97 \%$ & $204,60 \%$ \\
\hline & Máximo & 6,55 & 723,03 & 7,07 & 1135,43 & 167,46 \\
\hline & Mínimo & 1,54 & 3,72 & 1,83 & 8,32 & 1,23 \\
\hline \multirow{6}{*}{$\begin{array}{l}\text { 17alfa-hidroxi-progesterona } \\
\text { (ng/dL) }\end{array}$} & Média & 8,48 & 7,58 & 9,1 & 10,1 & 8,13 \\
\hline & Desvio Padrão & 3,89 & 3,97 & 4,36 & 5,55 & 6,23 \\
\hline & Variância & 15,14 & 15,79 & 18,99 & 30,79 & 38,87 \\
\hline & C. V. & $45,90 \%$ & $52,43 \%$ & $47,89 \%$ & $54,92 \%$ & $76,70 \%$ \\
\hline & Máximo & 17,44 & 22,09 & 20,01 & 26,34 & 38,89 \\
\hline & Mínimo & 3,21 & 2,46 & 1,93 & 2,2 & 2,15 \\
\hline
\end{tabular}


Tabela 4 - Análise de variância das concentrações de testosterona total, 17beta-estradiol e 17alfa-hidroxi-progesterona entre pirarucus, Arapaima gigas, de sexos diferentes e do mesmo grupo.

\begin{tabular}{llll}
\hline Variável & Machos & Fêmeas & Grupo \\
\hline \multirow{2}{*}{ Testosterona total (ng/dL) } & $542,43^{\mathrm{a}}$ & $112,18^{\mathrm{b}}$ & "A" \\
& $739,94^{\mathrm{a}}$ & $235,22^{\mathrm{b}}$ & "B" \\
\hline \multirow{2}{*}{ 17beta-estradiol (pg/mL) } & $3,36^{\mathrm{a}}$ & $35,25^{\mathrm{b}}$ & "A" \\
& $3,41^{\mathrm{a}}$ & $198,53^{\mathrm{b}}$ & "B" \\
\hline & $8,48^{\mathrm{a}}$ & $7,58^{\mathrm{a}}$ & "A" \\
17alfa-hidroxi-progesterona (ng/dL) & $4,36^{\mathrm{a}}$ & $5,55^{\mathrm{a}}$ & "B" \\
\hline
\end{tabular}

Médias seguidas de letras iquais, na mesma linha, não diferiram entre si pelo teste de Student-Newman-Keuls a 5\% de significância.

Tabela 6 - Valores do índice de correlação de Pearson (r) e nível de probabilidade de erro (p) entre as concentrações de testosterona total, 17betaestradiol e 17alfa-hidroxiprogesterona em machos de pirarucu, Arapaima gigas, do grupo "A".

\begin{tabular}{|c|c|c|c|c|}
\hline $\mathrm{GL}=46$ & $P$ & \multirow{2}{*}{$\begin{array}{l}\text { Testosterona } \\
\text { total }\end{array}$} & \multirow{2}{*}{$\begin{array}{l}\text { 17beta- } \\
\text { estradiol }\end{array}$} & \multirow{2}{*}{$\begin{array}{l}\text { 17alfa-hidroxi- } \\
\text { progesterona }\end{array}$} \\
\hline $\mathrm{R}$ & & & & \\
\hline \multicolumn{2}{|c|}{ Testosterona total } & & 0,0021 & 0,4878 \\
\hline \multicolumn{2}{|c|}{ 17beta-estradiol } & 0,4332 & & 0,9366 \\
\hline \multicolumn{2}{|c|}{$\begin{array}{l}\text { 17alfa-hidroxi- } \\
\text { progesterona }\end{array}$} & 0,1026 & 0,0118 & \\
\hline
\end{tabular}

Tabela 7 - Valores do índice de correlação de Pearson (r) e nível de probabilidade de erro ( $p$ ) entre as concentrações de testosterona total, 17betaestradiol e 17alfa-hidroxiprogesterona em fêmeas de pirarucu, Arapaima gigas, do grupo "A".

\begin{tabular}{|c|c|c|c|}
\hline $\mathrm{GL}=58 \quad \mathrm{P}$ & Testosterona & 17beta- & 17alfa-hidroxi- \\
\hline$r$ & total & estradiol & progesterona \\
\hline Testosterona total & & 0,4319 & 0,0416 \\
\hline 17beta-estradiol & $-0,1034$ & & 0,4821 \\
\hline $\begin{array}{l}\text { 17alfa-hidroxi- } \\
\text { progesterona }\end{array}$ & $-0,2638$ & 0,0925 & \\
\hline
\end{tabular}

Tabela 5 - Análise de variância das concentrações de testosterona total, 17beta-estradiol e 17alfa-hidroxi-progesterona entre pirarucus, Arapaima gigas, de sexos iguais e de grupos diferentes.

\begin{tabular}{llll}
\hline Variável & Grupo “A” & Grupo "B” & Sexo \\
\hline \multirow{2}{*}{ Testosterona total (ng/dL) } & $542,43^{\mathrm{a}}$ & $739,94^{\mathrm{b}}$ & Machos \\
\hline & $112,18^{\mathrm{a}}$ & $235,22^{\mathrm{b}}$ & Fêmeas \\
\hline 17beta-estradiol (pg/mL) & $3,26^{\mathrm{a}}$ & $3,41^{\mathrm{a}}$ & Machos \\
\hline & $35,25^{\mathrm{a}}$ & $198,53^{\mathrm{b}}$ & Fêmeas \\
\hline 17alfa-hidroxi-progesterona (ng/dL) & $8,48^{\mathrm{a}}$ & $9,1^{\mathrm{a}}$ & Machos \\
& $7,58^{\mathrm{a}}$ & $10,10^{\mathrm{b}}$ & Fêmeas \\
\hline
\end{tabular}

Médias seguidas de letras iguais, na mesma linha, não diferiram entre si pelo teste de Student-Newman-Keuls a 5\% de significância.

As Tabelas 8 e 9 apresentam a correlaçáo entre testosterona, 17beta-estradiol e 17alfa-hidroxi-progesterona de machos e fêmeas, respectivamente, do grupo "B". Em ambos os sexos, existiu uma correlação entre a variação de testosterona e 17beta-estradiol, sendo esta mais forte nas fêmeas.

Tabela 8 - Valores do índice de correlação de Pearson (r) e nível de probabilidade de erro (p) entre as concentrações de testosterona total, 17betaestradiol e 17alfa-hidroxiprogesterona em machos de pirarucu, Arapaima gigas, do grupo "B".

\begin{tabular}{|c|c|c|c|}
\hline $\mathrm{GL}=46$ & \multirow{2}{*}{$\begin{array}{l}\text { Testosterona } \\
\text { total }\end{array}$} & \multirow{2}{*}{$\begin{array}{l}\text { 17beta- } \\
\text { estradiol }\end{array}$} & \multirow{2}{*}{$\begin{array}{l}\text { 17alfa-hidroxi- } \\
\text { progesterona }\end{array}$} \\
\hline R & & & \\
\hline Testosterona total & & 0,0021 & 0,4878 \\
\hline 17beta-estradiol & 0,4332 & & 0,9366 \\
\hline $\begin{array}{l}\text { 17alfa-hidroxi- } \\
\text { progesterona }\end{array}$ & 0,1026 & 0,0118 & \\
\hline
\end{tabular}

Tabela 9 - Valores do índice de correlação de Pearson (r) e nível de probabilidade de erro ( $p$ ) entre as concentrações de testosterona total, 17betaestradiol e 17alfa-hidroxiprogesterona em fêmeas de pirarucu, Arapaima gigas, do grupo "B".

\begin{tabular}{|c|c|c|c|c|}
\hline $\mathrm{GL}=46$ & $P$ & \multirow{2}{*}{$\begin{array}{l}\text { Testosterona } \\
\text { total }\end{array}$} & \multirow{2}{*}{$\begin{array}{l}\text { 17beta- } \\
\text { estradiol }\end{array}$} & \multirow{2}{*}{$\begin{array}{l}\text { 17alfa-hidroxi- } \\
\text { progesterona }\end{array}$} \\
\hline$R$ & & & & \\
\hline \multicolumn{2}{|c|}{ Testosterona total } & & 0,0001 & 0,9483 \\
\hline \multicolumn{2}{|c|}{ 17beta-estradiol } & 0,8446 & & 0,7741 \\
\hline $\begin{array}{l}\text { 17alfa-hi } \\
\text { progester }\end{array}$ & $\begin{array}{l}\text { droxi- } \\
\text { rona }\end{array}$ & 0,0096 & $-0,0425$ & \\
\hline
\end{tabular}




\section{DISCUSSÃO}

Com relação ao comportamento reprodutivo do pirarucu, Arapaima gigas, Fontenele (1952) registrou a falta de interesse por alimento como um sinal precursor da reprodução. As brigas foram relatadas por Imbiriba (1991) como um processo de isolamento da área de postura. Esses comportamentos, junto com o aparecimento de ninhos, observados neste experimento, corroboram estas informações.

As brigas observadas para os pirarucus neste experimento denotaram claramente o comportamento de corte e de territorialidade, e no ambiente natural é comum observar uma espécie de "nuvem escura" formada pelas larvas, se deslocando junto ao macho que as protegem contra predadores (Fontenele, 1952).

Imbiriba (1991) relatou a existência de ninhos de mais ou menos $50 \mathrm{~cm}$ de diâmetro em tanques com fundo menos resistentes, rico em sedimentos, corroborando as observaçôes de Fontenele (1952). Os ninhos encontrados durante o presente estudo foram semelhantes àqueles encontrados por Imbiriba (1991).

Balon $(1975,1984,1985)$ apresentou uma classificação dos estilos reprodutivos em peixes de água doce, considerando três grandes grupos: não guardadores, que não protegem seus ovos e larvas, guardadores, que cuidam dos ovos e embrióes, e carregadores, que carregam os embrióes e algumas vezes os juvenis. Vazzoler (1996) ainda ressalta que os guardadores, às vezes, também cuidam de sua progênie, sendo comum apresentarem comportamento de corte elaborado e territorialidade. De acordo com esta classificaçáo o pirarucu pode ser considerado como guardador, e desova em ninhos do tipo buraco.

Fontenele (1952) observou que há uma mudança na coloração, com o enegrecimento da cabeça e região dorsal, e que essa mudança é um caráter sexual secundário do macho de pirarucu. No entanto, nâo foi possível observar o enegrecimento dos exemplares machos neste experimento. Bard e Imbiriba (1986) corroboraram as observaçóes de Fontenele (1952) e relataram que essa mudança ocorre com maior ênfase na época das chuvas, que coincide com o período de reprodução desta espécie.

Empiricamente, os pescadores da região separam machos e fêmeas de pirarucu através do tamanho da cabeça, largura do corpo e manchas alaranjadas na parte inferior da cabeça. Neste experimento, as manchas alaranjadas na regiāo inferior da cabeça foram características dos machos, aspecto confirmado através do perfil hormonal desses peixes, que apresentaram maior concentração do hormônio sexual masculino (testosterona).

Adotando o termo estresse como resposta do organismo e estressor como o estímulo causador desta resposta, observou- se que vários estressores estiveram presentes ao longo do experimento, desde a alta densidade de estocagem no viveiro, mencionada acima, até o manejo mensal para a coleta de sangue.

Segundo Graef (1995), o pirarucu chega à maturidade sexual do $3^{\circ}$ ao $5^{\circ}$ ano de vida. Lüling (1964) relatou que o começo da maturidade sexual do pirarucu em cativeiro pode ser atrasado consideravelmente, desde que os reprodutores sejam perturbados. Schreck (1981) e Wendelaar-Bonga (1997) apud Schreck et al. (2001) reportaram que inúmeros fatores podem contribuir para a atenuação do estresse, tais como o gênero, idade, estaçâo do ano, condiçóes físicas, hierarquia, qualidade de água, entre outros.

Com relação à caracterização hormonal de teleósteos, Poortenaar et al. (2001) evidenciaram o aumento de concentraçấo de $\mathrm{E}_{2}$ nas fêmeas de Seriola lalandi lalandi durante a vitelogênese, o mesmo ocorreu para Anguilla japonica (Matsubara et al., 2005), Salmo salar (Lacroix et al., 1997), Perca fluviatilis (Noaksson et al., 2005), Acheilognathus rhombea (AIDA, 1988).

Harvey e Carolsfeld (1993) descrevem que as altas concentraçóes de estradiol $\left(\mathrm{E}_{2}\right)$ estimulam a síntese de um precursor do vitelo, chamado vitelogenina, que é incorporado pelos oócitos, sob a ação do GtH I. No grupo "A", as concentraçôes de $\mathrm{E}_{2}$ foram elevadas no mês de março, além de outros picos em maio, agosto, novembro e janeiro, e no grupo "B", nos meses de fevereiro, maio e janeiro, sugerindo que as fêmeas de pirarucu passaram por esta fase nesses meses.

Esses resultados corroboram a hipótese de que os picos de $E_{2}$ no pirarucu estáo relacionados com a vitelogênese, além da baixa concentraçáo deste hormônio nos machos. Essa suspeita é reforçada com a rejeição do alimento, brigas entre indivíduos e formação de ninhos um mês após os picos de $E_{2}$. Fontenele (1958) reportou que esses comportamentos antecedem a desova.

Fontenele (1958) descreveu oócitos de vários tamanhos em fêmeas desta espécie e concluiu que este é um peixe de desova parcelada. Imbiriba (2001) descreveu que, apesar de ser um peixe de desova parcelada, o maior número de reprodução acontece nos períodos chuvosos. Isso pode explicar os vários picos de $\mathrm{E}_{2}$ ao longo do experimento e a variaçáo diferente entre fêmeas demonstradas através da correlação de Pearson.

Harvey e Carolsfeld (1993) relataram que a T é sintetizada nas células de Leydig e atua no início da gametogênese dos machos de peixe. Os machos do grupo "A" e do grupo "B" tiveram concentraçôes de testosterona maiores que nas fêmeas $(\mathrm{p}<0,01)$. Os picos dos machos do grupo "A" foram nos meses de março, julho e janeiro. No grupo "B", os picos foram nos meses de fevereiro, maio e janeiro. Brigas, formação de ninhos 
e desinteresse por alimento foram observados um mês depois dos picos de $\mathrm{T}$.

O aumento das concentraçóes de $T$ podem estar ligados ao início da espermatogênese do pirarucu. Picos deste hormônio foram observados em Salmo salar nesta fase (Lacroix et al., 1997). No entanto, em Seriola lalandi lalandi, esses picos estão relacionados a machos com gametogênese parcialmente ou totalmente completa (Poortenaar et al. 2001).

Em fêmeas, as elevadas concentrações de $\mathrm{T}$ estáo relacionadas a diferentes estágios de desenvolvimento gonadal. Em Achilognathus rhombea, as concentraçóes de $\mathrm{T}$ são constantes na vitelogênese, com um aumento no início da maturação e queda no final (Aida, 1988). Em Cyprinus carpio, a $T$ varia positivamente com a gonadotropina, sugerindo ter uma atuação na maturação final dos oócitos (Aida, 1988). Perca fluviatilis tem altas concentraçóes de T na desova e caem logo após (Noaksson et al., 2005). Em Seriola lalandi lalandi, as concentraçóes de $\mathrm{T}$ são maiores durante a vitelogênese e maturação final dos oócitos (Poortenaar, 2001). E em Morone saxatilis, o aumento ocorre somente na migração da vesícula germinativa (Mylonas, et al., 1998).

Neste experimento, pode-se observar uma correlaçáo positiva entre a variação de $\mathrm{E}_{2} \mathrm{e} T$ nas fêmeas do grupo " $\mathrm{B}$ ". Provavelmente, esses peixes atingiram a fase III - vitelogênese, na qual as células especiais da teca sob o efeito da GtH I sintetizam a $T$, a qual estimula as células granulosas na síntese de $E_{2}$, e ambas estimulam o fígado na síntese de vitelogenina (Harvey e Carolsfeld, 1993). Aumentos da concentração destes hormônios precederam os comportamentos sexuais observados neste experimento reforçando sua participação nesta fase.

Elevadas concentraçóes de 17 aOHP foram encontradas em fêmeas de Perca fluviatilis durante a desova (Noaksson et al., 2005), o mesmo em Cyprinus carpio (Aida, 1988). Em Acheilonatus rhombea, as concentrações elevadas foram encontradas durante a maturação final dos oócitos (Aida, 1988).

Os picos de 17 aOHP foram observados em meses, nos quais a falta de interesse por alimento, brigas e formação de ninhos foi evidente. Isso sugeriu a atuação desse hormônio na maturação final dos oócitos do pirarucu.

Cerda et al. (1994a) apud Izquierdo et al. (2001) reportaram a redução dos níveis de $\mathrm{E}_{2}$ no plasma em detrimento a redução alimentar em Dicentrarchus labrax, criados em cativeiro. Cerda et al. (1995) concluíram que, nessa mesma espécie, existe uma forte relaçâo entre a composiçâo lipídica da dieta alimentar e o desenvolvimento gonadal, níveis de lipídeos e esteróides sexuais no plasma. Estes mesmos autores ainda relatam que as ausências de algumas substâncias em raçôes comerciais podem comprometer o desempenho reprodutivo.
Neste experimento, isso pode ter influenciado a diferença nos níveis de T entre machos de grupos diferentes e de T, 17 $\beta$ $\mathrm{E}_{2}$ e 17OHP entre fêmeas dos dois grupos, visto que as fêmeas do grupo "A" foram criadas em condiçôes inadequadas no ano anterior ao experimento. Além do tipo de alimentação, que para o grupo "B" foi mais completa, com raçáo balanceada e peixe forrageiro, e para o grupo "A" apenas peixe, tanto morto quanto forrageiro.

As variáveis físico-químicas da água mensuradas estavam dentro dos parâmetros normais verificados nos rios e lagos da regiáo amazônica (Sioli, 1991). Essas variaçóes também foram analisadas por Cavero et al. (2003) os quais descreveram que esta não influenciou no crescimento de juvenis de pirarucu criados em tanques-rede de pequeno volume.

Cavero et al. (2004) relataram a tolerância de juvenis de pirarucu ao aumento da concentraçáo de amônia, os quais toleraram $25 \mathrm{mg} / \mathrm{l}$ de amônia total, obtendo $100 \%$ de sobrevivência. Nos resultados obtidos no presente trabalho, a maior quantidade de amônia total encontrada foi $2,0 \mathrm{mg} / \mathrm{l}$.

As variações ambientais têm um papel muito importante para a reprodução de peixes, principalmente os da regiáo Amazônica. De acordo com Richer et al. (1982) e Lam (1983), as espécies tropicais têm um período reprodutivo relativamente longo e podem até reproduzir durante todo o ano. Em geral, a complexidade dos fatores ambientais relacionados com a reproduçáo é muito grande, envolvendo precipitaçáa, temperatura, incremento do nível das águas, diminuição da condutividade, $\mathrm{pH}$, ciclo lunar, fatores sociais e contaminação ambiental. Breton et al. (1980a, b) e Lam (1983) reportaram que as variáveis temperatura e precipitação são as mais importantes para o processo reprodutivo.

Bláquez et al. (1998) descreveram que o ciclo sazonal na reproduçáo é uma estratégia de muitos teleósteos para assegurar que o tempo de desova coincida com condiçôes ambientais compatíveis e disponibilidade de suprimento alimentar necessários para a sobrevivência e crescimento das larvas.

Endogenamente, o principal mecanismo de controle da reprodução nos peixes é constituído pelos sistemas endócrino e neuroendócrino, que realizam a ligação entre o ambiente e os órgãos relacionados à reprodução (Donaldson, 1972).

Imbiriba (2001) relatou que o pico da reprodução do pirarucu coincide com o período das chuvas. Os ribeirinhos relatam empiricamente, para a espécie, a realização de pequenas migraçốes e que, sugestivamente este comportamento tem ligação com a escolha do local de desova, geralmente escolhidos em locais perto da foz de rios de água branca, que são aqueles com maiores níveis de oxigênio dissolvido. Este fato sugere mais uma estratégia de proteção a prole do pirarucu, visto que a troca gasosa nas larvas é realizada pelas brânquias e por 
isso, o pirarucu, em suas fases iniciais necessita de oxigênio dissolvido na água.

Neste experimento, os picos de testosterona, 17betaestradiol e 17alfa-hidroxi-progesterona nos peixes dos grupos "A" e "B" foram registrados em períodos de grande precipitação e temperaturas elevadas, denotando que em função da idade, estes foram os indivíduos mais preparados fisiologicamente para a reprodução.

Zohar e Mylonas (2001) citaram várias disfunções reprodutivas de peixes quando criados em cativeiro. Donaldson (1996) ressaltou que a reproduçáo em cativeiro tem sido considerada a chave que abre a porta para o sucesso das primeiras fases larvais, metamorfoses e engorda até o tamanho comercial.

\section{CONCLUSÕES}

A mancha alaranjada na regiáo inferior da cabeça, indicada empiricamente pelos ribeirinhos, foi comprovadamente uma característica sexual secundária do macho, corroborada pelo perfil hormonal dos esteróides sexuais.

A variação hormonal nas fêmeas de pirarucus, Arapaima gigas, do grupo "B" ( $3-4$ anos) indicaram um maior preparo fisiológico para a reprodução do que a observada nas fêmeas do grupo "A" (> 4 anos).

As fêmeas do grupo "B" alocaram energia para a reproduçáo refletindo no perfil hormonal, principalmente na concentração de 17beta-estradiol.

\section{BIBLIOGRAFIA CITADA}

AIDA, K. A review of plasma hormone changes during ovulation in cyprinid fishes. Aquaculture, Amsterdam, v. 74, p. 11-21. 1988.

ALCÁNTARA, F. B.; GUERRA, H. F. Culture of paiche, Arapaima gigas, using the bujurqui, Cichlassoma bimaculatum, like prey. Folia Amazônica, Iquitos, v. 4, n. 1, p. 129 - 139, jan. 1992 (In Spanish, with abstract in English).

BARD, J.; IMBIRIBA, E. P. Pisciculture pirarucu, Arapaima gigas. Belém: EMBRAPA-CPATU, 1986. 17p. (Circular Técnica, 52) (In Portuguese).

BALON, E. K. Patterns in the evolution of reproduction styles in fishes. In: POTTS, G. W., WOOTTON, R. J. (eds.) Fish reproduction: strategies and tactics. London: Academic Press, 1984. p. 35-53.

BALON, E. K. Early life histories of fishes: new development, ecological and evolutionary perspectives. Dordrecht: Dr. W. Junk Publishers, 1985. 280p.

BALON, E. K. Reproductive guilds of fishes: a proposal and a definition. J. Fish. Bd. Can., v. 32, p. 821-864, Jun. 1975.

BILLARD, R. et al. Endocrine control of spermatogenesis in teleost fish. Canadian Journal of Fish Aquatic Sciencies. Ottawa, v. 39, p. 65-79, Fev. 1982.
BILLARD, R.; BRETON, B.; FOSTIER, A.; JALABERT, B; WEIL, C. Endocrine control of teleost reprodutive cicle and its relation to external factors: Salmonids and cyprinids models. In: GAILLARD, P. J.; BOER, H. H. Comparative Endocrinology. Amsterdam: Elsevier, 1978. cap. 3, p. 37-48.

BLÁZQUEZ, M.; BOSMA, P. T.; FRASER, E. J.; VAN LOOK, K. J. W.; TRUDEAU, V. L. Fish as model for the neuroendocrine reulation of reproduction and growth. Comparative Biochemistry and Physiology, Amsterdam, v. 119c, p. 345-364, 1998.

BRAUNER, C. J.; VAL, A. L. The interaction between $\mathrm{O}_{2}$ and $\mathrm{CO}_{2}$ exchange in the obligate ai breather, Arapaima gigas, and the facultative air breather, Lipossarcus pardalis. In: VAL, A. L.; ALMEIDA-VAL, V. M. F.; RANDALL, D. J. (Ed.). Physiology and biochemistry of the fishes of the Amazon. Manaus: Instituto Nacional de Pesquisas da Amazônia, 1996. cap. 9, p.101-110.

BRETON, B.; HOROSZEWICZ, L.; BIENIARZ, K.; EPLER, P. Temperature and reproduction in fish: effect of a ride in the annual temperature regime gonadotropin level, gametogenesis and spawing. I. The male. Reprod. Nutri. Develop. v. 20, p.105228, 1980a.

BRETON, B.; HOROSZEWICZ, L.; BIENIARZ, K.; EPLER, $\mathrm{P}$. Temperature and reproduction in fish: effect of a ride in the annual temperature regime gonadotropin level, gametogenesis and spawing. II. The female. Reprod. Nutri. Develop. v. 20, p.1011-1024, 1980b.

CARVAlHO, L. O. D. de M.; NASCIMENTO, C. N. B. do. Fattening pirarucu (Arapaima gigas) in association with buffalo and pigs. Belém, EMBRAPA-CPATU, 1992. 21p. (Circular técnica, 65) (In Portuguese).

CAVERO, B. A. S.; PEREIRA-FILHO, M.; ROUBACH, R.; ITUASSÚ, D. R.; GANDRA, A. L.; CRESCÊNCIO, R. Stock density effect in growing homogeny of young pirarucu in captivity. Pesquisa Agropecuária Brasileira, Brasília, v. 38, n. 1, p. 103-107, jan. 2003 (In Portuguese, with abstract in English).

CAVERO, B. A. S.; PEREIRA-FILHO, M.; BORDINHON, A. M.; FONSECA, F. A. L.; ITUASSÚ, D. R.; ROUBACH, R.; $\mathrm{ONO}, \mathrm{E}$. A. Tolerance of pirarucu the increased concentration of ammonia in confined environment. Pesquisa Agropecuária Brasileira, Brasília, v. 39, n. 5, p. 513 - 516, maio. 2004 (In Portuguese, with abstract in English).

CERDÁ, J.; ZANUY, S.; CARRILLO, M.; RAMOS, J.; SERRANO, R. Short- and long-term dietary effects on female sea bass (Dicentrarchus labrax): seasonal changes in plasma profiles of lipids and sex steroids in relation to reproduction. Comparative Biochemistry and Physiology, Amsterdam, v. 111c, p. 83-91, 1995.

CRESCÊNCIO, R. Feed training of pirarucu, Arapaima gigas (CUVIER, 1829) fingerlings, using food baits. 2001. $35 \mathrm{f}$. Dissertação de Mestrado, Instituto Nacional de Pesquisas da Amazônia, Manaus. (In Portuguese).

DEMSKI, L. S.; HORNBY, P. J. Hormonal control of fish reproductive behavior: brain - gonadal steriod interactions. Canadian Journal of Fish Aquatic Sciencies. Ottawa, v. 39, p. 36-47, fev. 1982. 
DONALDSON, E. M. Manipulation of reproduction in farmed fish. Animal Reproduction Science, Amsterdam, v. 42, p. 381392, 1996.

DONALDSON, E. M. Physiological and phyiochemical factors associated with maturation and spawning. In: WORKSHOP ON CONTROLLED REPRODUCTION OF CULTIVED FISHES. EIFAC tec.1972. 53-73.

FERRARIS J.R., C. J. Family Arapaimatidae (Bonytougues). In: REIS, R. E.; KULLANDER, S. O.; FERRARIS J.R., C. J. (org.). Check list of the freshwater fishes of South and Central America. Porto Alegre: Edipucrs, 2003. 742p.

FONTENELE, O. Contribution to the knowledge of the biology of pirarucu, Arapaima gigas (Cuvier) in captivity (Actinopterygii, Osteoglossidae). Revista Brasileira de Biologia, Rio de Janeiro, v. 8, n. 4, p. 445-459, dez. 1948. (In Portuguese, with abstract in English).

FONTENELE, O. Spawning habits pirarucu, Arapaima gigas (Cuvier) (Pisces: Isospondyli, Arapaimidae), and growth of their larvae. Fortaleza, DNOCS, 1952. 22p. (Publicação n. 153) (In Portuguese).

GRAEF, E. W. Fish species with potential for farming in the Amazon. In: VAL, A. L.; Honczaryk, A. Creating fish in the Amazon. Manaus: INPA, 1995. cap. 4, p. 29-43 (In Portuguese).

HARVEY, B.; CAROLSFELD, J. Fish reproductive endocrinology. In:____ Induced breeding in tropical fish culture. Ottawa: IDRC, 1993. cap. 2, p. 5-33.

HOAR, W. S. Reproduction. In: HOAR, W. S.; RANDALL, D. J. Fish Physiology. New York: Academic Press, 1969. cap. 1, p. 1-72.

HONCZARYK, A. MAEDA, L. Growth pirarucu Arapaima gigas, using a diet based on ensiled fish. In: SIMPÓSIO BRASILEIRO DE AQÜICULTURA, 1998, Recife. Anais. Recife, 1998, 93100 (In Portuguese).

IMBIRIBA, E. P.; BARD, S.; MOURA CARBALHO, L.D.D.; NASCIMENTO, C.N.S.; SOUZA, J.C.M. Preliminary results of the creation of pirarucu, Arapaima gigas (Cuvier) in captivity. Belém: EMBRAPA-CPATU, 1985. 4p. (Circular técnica, 144) (In Portuguese).

IMBIRIBA, E. P. Creation potential pirarucu, Arapaima gigas, in captivity. Acta Amazônica, Manaus, v. 31, n. 2, p. 299-316, 2001 (In Portuguese, with abstract in English).

IMBIRIBA, E. P. Production and management of fingerlings pirarucu, Arapaima gigas (Cuvier). Belém: EMBRAPA-CPATU, 1991. 19p. (Circular técnica, 57) (In Portuguese).

ITUASSÚ, D. R. Protein requirements of young pirarucu, Arapaima gigas (Cuvier, 1829). 2002. 38f. Dissertação de Mestrado, Instituto Nacional de Pesquisas da Amazônia, Manaus (In Portuguese).

IZQUIERDO, M. S.; FERNÁNDEZ-PALACIOS, H.; TACON, A. G. J. Effect of broodstock nutrition on reprodutive performance of fish. Aquaculture, Amsterdam, v. 197, p. 25-42. 2001.

LACROIX, G. L. et al. Absence of seasonal changes in reprodutive function of cultured Atlantic salmon migrating into a Canadian river. Journal of Marine Sciences, Dauphin, v. 54, p. 1086-1091, 1997.
LAM, T. J. Applications of endocrinology to fish culture. Canadian Journal of Fish Aquatic Sciences. Ottawa, v. 39, p. 111-137, Fev. 1982.

LAM, T. J. Enviromental influences on gonadal activity in fish. In: HOAR, W. S.; RANDALL, D. J.; DONALDSON, E. M. Fish Physiology. New York: Academic Press, 1983. cap. 2, p. 65-116.

LÜLING, K. H. The biology and ecology of Arapaima gigas (Pisces. Osteoglossidae). Zoologie 'Morph, Ökol, v. 54, p. 436-530, 1964. (In Germany)

MATSUBARA, H.; KAZETO, Y.; IJIRI, S.; HIRAI, T.; ADACHI, S.; YAMAUCHI, K. Serum steroid profiles in artificially maturing female Japanese eel, Anguila japonica. Aquaculture, Amsterdam, v. 243, p. 393-402, 2005.

MATSUYAMA, M; YOSHIHIDE, H.; MATSUURA, S. Effects of steroids on germinal vesicle breakdown in vitro of intact follicules in the japonese whiting, Sillago japonica, a marine teleost. Comparative Biochemistry and Physiology, Amsterdam, v. 96, p. 257-261, 1990.

MYLONAS, C.C.; WOODS III, L.C.; THOMAS, P.; ZOHAR, Y. Endocrine profiles of females striped bass (Morone saxatilis) in captivity, during postvitellogenesis and induction of final oocyte maturation via controlled-release GnRHa-delivery systems. General and Comparative Endocrinology, Amsterdam, v. 110, p. 276-289, 1998.

NAGAHAMA, Y.; KAGAWA, H.; YOUNG, G. Cellular sources of sex steroids in teleost gonads. Canadian Journal of Fish Aquatic Sciencies. Ottawa, v. 39, p. 56-64, fev. 1982.

NEVES, A. M. B. Current knowledge about the pirarucu. Belém: Museu Paraense Emílio Goeldi, 1995. p. 33-56 (Ser. Zool. 11) (In Portuguese).

NOAKSSON, E.; LINDEROTH, M.; GUSTAVSSON, B.; ZEBÜHR, Y.; BALK, L. Reproductive status in female perch (Perca fluviatus) outside a sewage treatment plant processing leachate from a refuse dump. Science of the Total Environment, Mar 20;340(1-3):97-112, 2005.

PANDURO-MENDOZA, G.; PORTUGAL-FALCON, V. Evaluation of growth of Paiche (Arapaima gigas) Fed with live and dead fish during the fattening phase in controlled environments, Iquitos (Perú). In: CONGRESSO IBEROAMERICANO VIRTUAL DE ACUICULTURA - CIVA, 2004. Disponível em: <http://www.civa2004.org> , 808-813. Acesso em: 22 nov. 2004 (In Spanish).

PETER, R. E. Neuro endocrine control of reproduction in teleosts. Canadian Journal of Fish Aquatic Sciences. Ottawa, v. 39, p. 48-55, Fev. 1982.

POORTENAAR, C. W.; HOOKER, S. H.; SHARP, N. Assessment of yellowtail kingfish (Seriola lalandi lalandi) reproductive physiology, as a basis for aquaculture development. Aquaculture, Amsterdam, v. 201, p. 271-286, 2001.

QUEIROS, H. L.; SARDINHA, A. D. Conservation and the sustainable use of pirarucus. In: QUEIROS, H. L.; CRAMPTON, W. G. R. Strategies for management of fish resources in Mamiraua. Brasília: CNPq. 1999. p. 108-141 (In Portuguese). 
RICHTER, C. J. J. et. al. Effects of fedding levels and temperature on the development of the gonad in the african catfish, Clarias lazera. Proc. Int. Symp. Reprod. Physiol. Fish. Wageningen, p. 52, 1982.

SCHRECK, C. B.; CONTRERAS-SANCHEZ, W.; FITZPATRICK, M. S. Effects of stress on fish reproduction, gamete quality, and progeny. . Aquaculture, Amsterdam, v. 197, p. 3-24, 2001.

SHERWOOD, N. The GnRH family of peptides. TINS, Amsterdam, v. 10, n. 3, p. 129-132. 1987

SIOLI, H. Amazon, the fundamentals of ecology of most tropical forest region. 3. ed. Petrópolis: Vozes, 1991. 73p (In Portuguese).

STACEY, N. E.; GOETZ, F. W. Role of prostaglandins in fish reproductoin. Canadian Journal of Fish Aquatic Sciencies, Ottawa, v. 39, p. 92-98, Fev. 1982.

VAZZOLER, A. E. A. de M. Reproductive biology of teleost fishes: theory and practice. Maringá: EDUEM. 1996. p. 169 (In Portuguese).

VENTURIERI, R.; BERNARDINO, G. Arapaima: Endangered species can be saved through culture. Panorama da Aqüicultura, Rio de Janeiro, v. 9, n. 53, p. 13-21, 1999 (In Portuguese).
YARON, Z.; ZOHAR, Y. An overview. In: MUIR, J. F.; ROBERTS, R. J. (Ed.). Recents advances in aquaculture 4. Oxford: Blackwell Scientific Publications, 1993. cap. 1, p.03-10.

YOUNG, G.; ADACHI, S.; NAGAHAMA, Y. Role of ovarian thecal and granulosa layers in gonadotropin-induced synthesis of a salmonid maturation-inducing substance (17a, 20b-dihydroxy4-pregnen-3-one). Developmental Biology, San Diego, v. 118, p. $1-8,1986$.

ZANUY, S.; CARRILLO, M. The teleost reproduction and its application in aquaculture In: MONTEROS, J. E. de los; LABARTA, U. Reproduction in Aquaculture, Madrid: Industrias Gráficas Espana, 1987. cap. 1, p. 1-131 (In Spanish).

ZOHAR, Y.; MYLONAS, C. C. Endocrine manipulations of spawning in cultured fish: from hormones to genes. Aquaculture, Amsterdam, v. 197, p. 99-136, 2001.

Recebido em 28/11/2007

Aceito em 24/11/2009 